\title{
A new validated high-performance liquid chromatography method for standardization of rosmarinic acid in Salvia extracts
}

\author{
Mustafa Ghanadian $^{1,2}$, Nahal Shamaeezadeh ${ }^{2}$, Pardis Mohammadi ${ }^{2}$, Maryam Mohajeri ${ }^{*}$ \\ ${ }^{1}$ Isfahan Pharmaceutical Sciences Research Center, Isfahan University of Medical Sciences, Isfahan, Iran \\ ${ }^{2}$ Department of Pharmacognosy, School of Pharmacy, Isfahan University of Medical Sciences, Isfahan, Iran
}

\section{A R T I C L E IN F O}

Article Type:

Original Article

\section{Article History:}

Received: 10 July 2017

Accepted: 19 August 2017

\section{Keywords:}

High Pressure Liquid

Chromatography, Rosmarinic acid, Salvia ceratophylla, Salvia chloroleuca, Salvia macrosiphon, Salvia nemorosa

\begin{abstract}
A B S T R A C T
Introduction: Tea bags or infuses of Salvia species from Lamiaceae family are traditionally used for the treatment of cough, and throat inflammations. They are known for antioxidant properties mainly related to the presence of rosmarinic acid (RA). Therefore it is necessary to develop a reliable analytical method for RA assay for standardization of Salvia species and also other plants containing RA like Melissa, Origanum, Lavandula, Rosmarinus, Thymus, Zataria, Mentha, Perovskia, Zhumeria, and Satureja species. In this study using a suitable extraction method by removing unwanted components present in crude methanol extract, phenolic content containing RA was extracted from dry powders of six Salvia species. Then, a suitable high-performance liquid chromatographic (HPLC) method was optimized for quantification of RA in Salvia species.

Methods: HPLC analysis was done on a Waters system, equipped with 515 HPLC pump and waters 2487 dual wavelength absorbance detector. The column was a Nova-Pak C18 $(3.9 \times 150 \mathrm{~mm})$, and Millenium software was used for the determination of the compounds and processing the data. The method was validated according to USP 32 requirements.

Results: Among the investigated 6 species, $S$. virgata was the richest in RA level, demonstrating $3.50 \pm 0.12 \mathrm{mg} / \mathrm{g}$, followed by $S$. sclarea and S. chloroleuca showing $1.65 \pm 0.08$ and $1.65 \pm 0.21 \mathrm{mg} / \mathrm{g}$. S. ceratophylla with $0.10 \pm 0.01 \mathrm{mg} / \mathrm{g}$ of RA in dried plant powder was the poorest.

Conclusion: The validated HPLC method allows determination of amounts as low as $2.5 \mu \mathrm{g} /$ $\mathrm{mL}$ of RA and linearity in the ranges of $2.5-25 \mu \mathrm{g} / \mathrm{mL}$ and $100-600 \mu \mathrm{g} / \mathrm{mL}$, which is suitable for standardization of Salvia species in traditional and pharmaceutical formulations.
\end{abstract}

Implication for health policy/practice/research/medical education:

In the present study, a new validated HPLC method was developed which is suitable for analysis of rosmarinic acid and standardization of Labiateae family plants like Salvia, Melissa, Origanum, Lavandula, Rosmarinus, Thymus, Zataria, Mentha, Perovskia, Zhumeria, and Satureja species.

Please cite this paper as: Ghanadian M, Shamaeezadeh N, Mohammadi P, Mohajeri M. A new validated high-performance liquid chromatography method for standardization of rosmarinic acid in Salvia extracts. J Herbmed Pharmacol. 2018;7(1):44-50. doi: $10.15171 /$ jhp.2018.08.

\section{Introduction}

Tea bags or infuses of Salvia species from Lamiaceae family are traditionally used for the treatment of bronchitis, cough, and throat inflammations (1). They are known for antioxidant properties mainly related to the presence of dicaffeic acid derivatives like rosmarinic acid (RA) (2). In Chinese medicine, they are used in neurodegenerative diseases like Alzheimer disease (3) and recently, the cytoprotective effects of RA in sage extract against amyloid beta plaques formation was reported (4). They are used traditionally against diabetes and their glucoselowering affects are reported in animal models (5). Sage extract is also used as an antibacterial and deodorant agent in deodorant sticks and has reducing effects on sweating, and menopausal hot flashes $(6,7)$. A variety of different secondary metabolites like essential oils, polycyclic aromatic diterpenes, methoxylated flavones, and caffeic acid derivatives have been isolated from the

*Corresponding author: Maryam Mohajeri, Isfahan Pharmaceutical Sciences Research Center, Isfahan University of Medical Sciences, Isfahan, IR Iran. Tel: +98-9199023259,

Email: maryam.mohajeri66@gmail.com 
genus, and are reported in the literature $(1,2)$. However, the main property of Salvia species is their antioxidative effect mostly related to their caffeic acid derivatives and especially RA (2). Antioxidant properties of total extracts of Salvia virgata, Salvia staminea and Salvia verbenaca from Turkey were investigated by two different ways, namely DPPH free radical scavenging and $\beta$-carotene/ linoleic acid methods and proved the direct relationship between RA level and antioxidant activity in Salvia species (8). Therefore, it is necessary to develop a reasonable and reliable analytical method for RA assay to determine the antioxidative potential and the quality of plants especially for wild species. In this study, using a suitable extraction method by removing unwanted components present in crude methanol extract, phenolic content containing RA was extracted from dry powders of six Salvia species. Then, a suitable HPLC method was optimized for quantification of RA in Salvia species.

\section{Materials and Methods}

Collection and authentication of the plants

The aerial parts of Salvia species (Lamiaceae) were supplied from the Khorasan, Iran and was identified by Dr. L. Ghaem-maghami, Department of biology, Faculty of Science, University of Isfahan. Herbarium specimens of S. ceratophylla with voucher number: 36207, S. chloroleuca No. 36528, S. macrosiphon No. 43000, S. nemorosa No. 40912, S. sclarea No. 32961, and S. virgata No. 43965 were deposited in the herbarium center of the Faculty of Pharmacy, Mashhad University of Sciences (Iran).

\section{Instrumentation}

HPLC (High-performance liquid chromatographic) analysis was done on 515 HPLC pump, waters 2487 dual wavelength absorbance detector (Waters, Milford, MA, USA). The column was a Nova-Pak C18, $3.9 \times 150 \mathrm{~mm}$ (Waters, Milford, MA, USA) and Millenium software was used for the determination of compounds and processing the data.

\section{Chemicals}

Acetonitrile HPLC-grade solvent was purchased from Caledon Company (Canada). RA, as analytical standard, was purchased from Sigma-Aldrich Corporation, USA.

Sample preparation and cleanup procedure for analysis Aerial parts of each Salvia species were dried at room temperature in the dark, separately. $1 \mathrm{~g}$ of crushed dried powder was macerated in $10 \mathrm{~mL}$ of ethanol: water: NaHCO3 (65:30:5). After overnight maceration, and then ultrasonic radiation (20 minutes) it was filtrated and concentrated in vacuum by a rotary evaporating system at $40^{\circ} \mathrm{C}$. Using a separating funnel, it was partitioned between $2 \mathrm{~mL}$ dilute $\mathrm{HCl}$ and diethyl ether. After stirring, the organic upper phase was separated and aqueous lower phase was washed by diethyl ether two other sequential times. The combined extracts were then evaporated and dissolved in $6 \mathrm{~mL}$ of acetonitrile: Water (1:1) and sonicated for 2 minutes. The solution was then filtered through 0.45 $\mu \mathrm{m}$ syringe filters and transferred to end capped vials prior to HPLC analysis.

Determination of suitable wavelength

Since the HPLC analysis was based on UV absorption and because many other phenolics or aromatic diterpenes in Salvia species show UV spectra with $\lambda$ max in the range of 210-330 nm, a good selectivity depends highly on the molar absorption to be high enough for detection of low quantities of RA in its working range. It depends also on UV absorption of other ingredients especially those with retention time beyond the RA and mobile phase UV cut off point. UV spectrum of RA showed that $\lambda$ max absorption was 196, 221, 291, and $328 \mathrm{~nm}$. Among them, $\lambda \max$ of 328 with more molar absorption and better mobile phase (acetonitrile: water) UV cut off point, and less overlap with other bands in HPLC chromatogram was selected.

Preparation of the Standard Solutions

$1000 \mu \mathrm{g}$ analytical standards were diluted in $1 \mathrm{~mL}$ of HPLC-grade acetonitrile: water (1:1) to prepare the stock solution of $1000 \mu \mathrm{g} / \mathrm{mL}$. Different standard solutions were prepared by serially diluting the stock solution to concentrations of $600,500,400,200$, and $100 \mu \mathrm{g} / \mathrm{mL}$.

\section{Instrumentation and chromatographic conditions}

RA was determined through an external standard calibration method on a Waters HPLC 515 system, equipped with 2487 dual wavelength UV detector. External standard calibration is a simple method suitable for reproducible dilution volumes and injection volumes and if the recovery of an analyte is about $100 \%$, it can be expected to be similar for all expected samples. The chromatographic analysis was done on a reverse phase Nova-Pak C18, $3.9 \times 150 \mathrm{~mm}$ column (Waters, Milford, MA, USA). Temperature was maintained at $45^{\circ} \mathrm{C}$. The mobile phase was consisted of $\mathrm{CH}_{3} \mathrm{CN}: \mathrm{H}_{2} \mathrm{O}: \mathrm{H}_{3} \mathrm{PO}_{4}$ (54.5: 445: 0.5$)$ as solution (A) and $\mathrm{CH}_{3} \mathrm{CN}: \mathrm{H}_{2} \mathrm{O}(350: 150)$ as solution (B) with a stepwise gradient system with a flow rate of $0.8 \mathrm{ml} / \mathrm{min}$ while the separation time was 14 minutes and the injection volume was $5 \mu \mathrm{L}$. For quantitative analysis, the wavelength was set at $328 \mathrm{~nm}$ and data was collected by Millenium Chromatography Software (Build 1154, Waters Corporation, Milford, USA).

\section{Selectivity}

The selectivity was confirmed by HPLC analysis of RA in Salvia extracts. The ability of method to separate closely ingredients from RA band was calculated by assessing resolution, tailing factor and theoretical plate number. Resolution (Rs) is a function of theoretical number of plates $(\mathrm{N})$, separation factor $(\alpha)$, and the capacity factor (k). Identification of RA in chromatograms was done 
by spiking the sample with standard RA. $\mathrm{N}$ and Rs were respectively calculated by using equations, $\mathrm{N}=5.54\left(\mathrm{Rt}_{\mathrm{a}} /\right.$ $\left.\mathrm{W}_{1 / 2}\right)^{2}$, and $\mathrm{Rs}=2\left(\mathrm{Rt}_{\mathrm{a}}-\mathrm{Rt}_{\mathrm{b}}\right) /\left(\mathrm{W}_{\mathrm{a}}+\mathrm{W}_{\mathrm{b}}\right)$, where $\mathrm{Rt}_{\mathrm{a}}$, and $\mathrm{W}_{\mathrm{a}}$ are retention times and band width of $\mathrm{RA}, \mathrm{W}_{1 / 2}$ is peak width at half height of RA peak, and $\mathrm{Rt}_{\mathrm{b}}$ and $\mathrm{W}_{\mathrm{b}}$ are related to closed eluted peak to RA peak in chromatogram $(9,10)$. Tailing is a condition in which the target peak is skewed after the peak apex. It happens especially in gradient elution systems and where the mobile phase and stationary phase concentrations of solute are not in equilibrium especially in fast mobile phase flow or where there is a slow kinetic desorption from the stationary phase. Tailing factor was defined according to the US Pharmacopoeia through equation, $\mathrm{T}_{0.05}=\mathrm{W} / 2 * \mathrm{~W}_{0.05}$

Limits of detection and quantification

The minimum amount of analyte which can be detected reliably is often referred as LOD (limit of detection) and is a peak which its signal-to-noise ratio is at least 3:1. The minimum quantifiable amount (LOQ) is the concentration which can be quantified with a specified level of accuracy. LOQ was calculated by injecting different concentrations of standard with signal-to-noise ratios of 10, 15, 20, and 25 and calculating LOQ with certain level of precision with relative standard deviation (RSD) less than 6, experimentally $(9,11)$.

Repeatability and intermediate precision

Precision is a multivariate factor. It could be controlled by minimizing different sources of errors in quantification. One of these is integration error especially in unresolved peaks (Rs < 1.5) and in low standard concentrations (range beyond the LOQ). Other sources of error are injection error and instrument error which should be controlled by repeatability test. It was carried out by a simple intraday injection method by the same analyst through three repetitive injections of the standards within the selected range in one day (11).

There are also additional sources of errors like environmental errors and long-term variability that intermediate in analysis. It was calculated by interday precision method through quantification of three replicates of standards in the selected range in three consecutive days in a week in the same lab and same analyst $(n=9)$. For a precise and suitable method RSD less than 3 is required (12).

\section{Accuracy}

One of the methods to be assured from the accuracy of HPLC quantification method is recovery tests. It ensures that the real amount of component is measured. It was performed by adding the RA as standard beyond the amount in the real sample in $1 \mathrm{~g}$ of a blank powder. It was extracted as was mentioned in the sample preparation method. Then evaporated sample was solubilized into 6 $\mathrm{mL}$ of HPLC mobile phase solvent. Three determinations were carried out and the recovery percentage was calculated in every case (11).

\section{Results}

The HPLC method carried out in this study was aimed to optimize the resolution (Rs), reduce runtime, tailing factor, and limit of quantification of RA in Salvia species.

\section{Optimizing the extraction method}

Two extraction methods consisted of crude methanol extract and special method for extraction of phenolic components were compared to check the effect of the procedure on the extraction. Finally, for removing unwanted components present in crude methanol extract, and to increase resolution and separating factor, a special method was designed for removing unwanted materials. Phenolic content containing RA was extracted from dry powder in ethanol: water: $\mathrm{NaHCO} 3$ (65:30:5) to produce sodium rosmarinate which is a more watersoluble ionizable conjugate and improves the solubility and extraction rate. After filtration and concentration in vacuum for removing sugars, glycosides, and unwanted polar components present in residue, and to prevent additional interferences, phenolic content was back extracted using liquid extraction in a separating funnel by partitioning between dilute $\mathrm{HCl}$ and diethyl ether. In partitioning, when $\mathrm{RA}$ is in the ionized form $(\mathrm{pH}=9)$, it is more soluble in the aqueous phase. Likewise, when it is in protonated uncharged state $(\mathrm{pH}=1)$, it can be partitioned and transferred into the organic layer (diethyl ether phase). However in this study, for a good and more precise back extraction, using HPLC analysis, by selection of different organic solvents (diethyl ether, ethyl acetate, chloroform), and changing $\mathrm{pH}(7,4.5,3,1)$, by selection of diethyl ether as solvent and controlling the $\mathrm{pH}$ to 1 , the selectivity and recovery was checked and optimized.

\section{Method development}

For separation of RA, a conventional USP L1 column, Waters Nova-Pak C18: $3.9 \times 150 \mathrm{~mm}(4 \mu \mathrm{m})$, was selected. Then, using gradient method from $0 \%$ to $100 \%$ acetonitrile in water, the solvent composition suitable for RA elution from $10 \%$ to $70 \%$ was selected. Then, to improve the retention of $\mathrm{RA}$ as a weak acid, the $\mathrm{pH}$ of the mobile phase was controlled. The mobile phase $\mathrm{pH}$ could change the ionizable species of RA in solution which affects its retention and selectivity. It changes ionization of both RA and residual silanol groups of column. Reducing the $\mathrm{pH}$ to 2.8 by adding phosphoric acid (1\%) as modifier made both RA and silanol groups protonated and improved selectivity and peak tailing. Then, the column temperature was enhanced and kept constant to $40^{\circ} \mathrm{C}$ to reduce solvent viscosity, back pressure, and variation of retention time of analyte. Finally, the mobile phase was consisted of CH3CN:H2O:H3PO4 (54.5: 445: 0.5) as solution (A) and $\mathrm{CH} 3 \mathrm{CN}: \mathrm{H} 2 \mathrm{O}: \mathrm{H} 3 \mathrm{PO} 4$ (345.5:150: 0.5) as solution 
(B). It was started with A: B (100:0) hold for 2 minutes, then $0-100 \%$ B in 12 minutes, with equilibration with $0 \%-100 \%$ A for 4 minutes. The flow rate was $1 \mathrm{~mL} / \mathrm{min}$ and temperature was kept constant at $40^{\circ} \mathrm{C}$. UV detector was set to single wavelength mode at $328 \mathrm{~nm}$ with a time constant of 0.1 seconds. Small injection volume of $5 \mu \mathrm{L}$ was injected to increase resolution.

Determination of rosmarinic acid

Using high pressure liquid chromatography, RA was determined using external standard calibration method. The retention time was observed to be 9.1 minutes (Figure 1).

Linearity and range

Using USP 35-NF 30 definition of signal to noise ratio, the LOD and LOQ were calculated as $0.8 \mu \mathrm{g} / \mathrm{mL}$ and $2.5 \mu \mathrm{g} /$ $\mathrm{mL}$ for RA. Sensitivity expressing as the LOD and LOQ values could be reduced more in the case of using isocratic mobile phase system, or increasing the injection size, but the current gradient mobile phase system possessed better selectivity and resolution. As clear in Table 1, using the millennium processing software, the calibration curve was determined by linear regression in two different working ranges, the range of $2.5-25 \mu \mathrm{g} / \mathrm{mL}$ and the range of $100-$ $600 \mu \mathrm{g} / \mathrm{mL}$ (Figure 2).

\section{Precision}

The instrumental precision by intra-day results and intermediate precision through inter-day results of repetitive RA quantitated in different concentrations in the selected linear range, 100 to $600 \mu \mathrm{g} / \mathrm{mL}$, as are presented in Table 2.

\section{Accuracy}

Accuracy was evaluated as recovery test after spiking of $200 \mu \mathrm{g}$ of RA standard to $1 \mathrm{~g}$ of the Myrtus communis powder as blank powder. It was extracted as mentioned above in sample preparation. Three determinations were done and the recovery percentage was found to be $92.4 \pm$ $4.36 \%$.

Rosmarinic acid assay in sage samples

Figure 3 demonstrate HPLC chromatogram of sage samples and Table 3 reports the amounts of RAs in six sage samples collected from North East of Iran. Each value was the mean of three extractions. The content of RA ranged from 0.1 to $3.2 \mathrm{mg} / \mathrm{g}$ of dried powder.

\section{Discussion}

RA is found in some of Labiateae family plants like Salvia, Melissa, Origanum, Lavandula, Rosmarinus, Thymus, Zataria, Mentha, Perovskia, Zhumeria, and Satureja species (13). It is also found in species of the Boraginaceae and in some fern and hornwort species (14). The major problem in their use is the plant-to-plant variability of RA. Therefore, using a validated chromatographic method, RA as one of their main active ingredients should be assayed and standardized. Another problem was chlorophylls, glycosides, and unwanted secondary metabolites

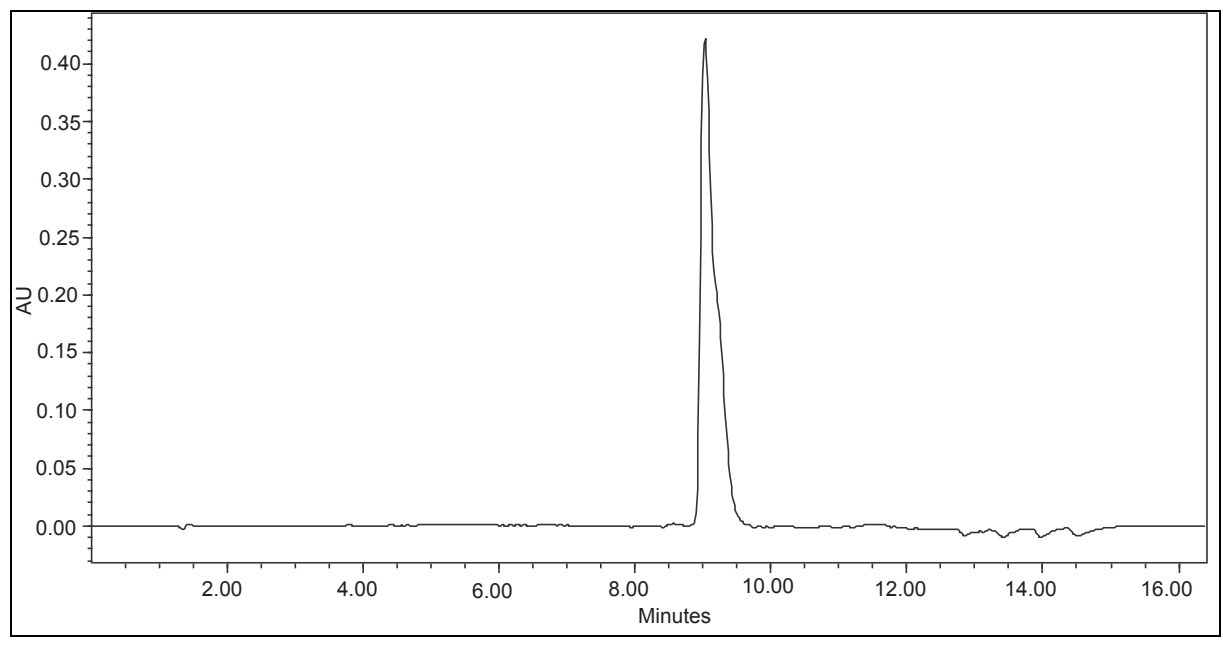

Figure 1. HPLC chromatogram of rosmarinic acid $(100 \mu \mathrm{g} / \mathrm{mL})$ at $328 \mathrm{~nm}$.

Table 1. Linearity, limit of detection and minimum quantifiable amount parameters of rosmarinic acid standard

\begin{tabular}{llllll}
\hline Compound & LOD $\mu \mathrm{g} / \mathrm{mL}$ & LOQ $\mu \mathrm{g} / \mathrm{mL}$ & $\mathbf{R}^{2}$ square & Equation & Linear range $(\mu \mathrm{g} / \mathrm{mL})$ \\
\hline Rosmarinic acid & 0.8 & 2.5 & 0.999 & $\mathrm{y}=26469 \mathrm{x}+1 \mathrm{E}+06$ & $100-600$ \\
Rosmarinic acid & 0.8 & 2.5 & 0.997 & $\mathrm{y}=26250 \mathrm{x}+14435$ & $2.5-25$ \\
\hline
\end{tabular}

Abbreviations: LOD, limit of detection; LOQ, limit of quantitation. 


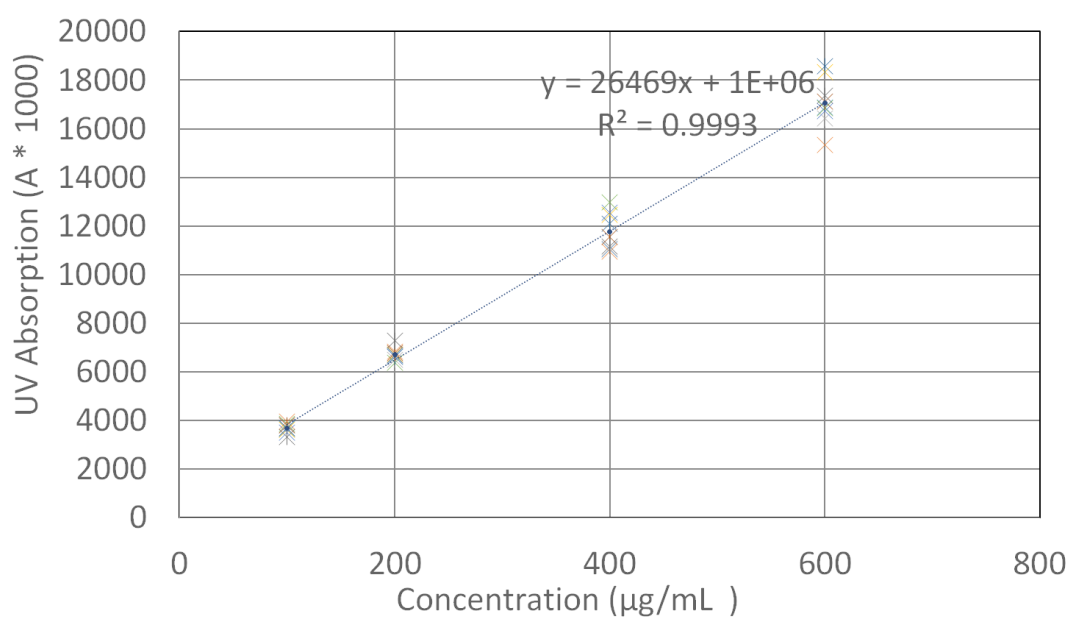

Figure 2. Calibration curve of Rosmarinic acid using HPLC method and acetonitrile: water as mobile phase with pH adjusted by adding $\mathrm{H}_{3} \mathrm{PO}_{4}$ to 2.8 at $328 \mathrm{~nm}$. Using the millennium processing software, the calibration curve was determined by linear regression in the range of $100-600 \mu \mathrm{g} / \mathrm{mL}$.

Table 2. Repeatability and intermediate precision assays of standards

\begin{tabular}{lllll}
\hline Concentrations $(\boldsymbol{\mu g} / \mathrm{mL})$ & Intra-day $(\mathbf{n}=\mathbf{9})$ & RSD\% & Intra-day $(\mathbf{n}=9)$ & RSD\% \\
\hline 100 & $3693023 \pm 149175$ & 4.0 & $3201392 \pm 195482$ & 6.1 \\
200 & $6716530 \pm 152209$ & 2.3 & $6723784 \pm 350657$ & 5.2 \\
400 & $11756892 \pm 786839$ & 6.7 & $11355005 \pm 338960$ & 3.0 \\
600 & $17064958 \pm 1033107$ & 6.1 & $16846497 \pm 810957$ & 4.8 \\
\hline
\end{tabular}

Abbreviation: RSD, relative standard deviation.

with overlapped peaks and interferences in HPLC chromatogram. Therefore, using a suitable extraction method by removing unwanted components present in crude methanol extract, phenolic content containing RA was extracted from dry powder. Then, a suitable HPLC method was optimized. It allowed determination of amounts as low as $2.5 \mu \mathrm{g} / \mathrm{mL}$ of RA and linearity in the ranges of $2.5-25 \mu \mathrm{g} / \mathrm{mL}$ and $100-600 \mu \mathrm{g} / \mathrm{mL}$. Finally, RA levels of 6 Salvia species grows wild in North-East of Iran were determined via HPLC validated method. The obtained results were summarized in Table 3. Among the investigated 6 species, S. virgata was the richest in RA level, demonstrating $3.50 \pm 0.12 \mathrm{mg} / \mathrm{g}$, followed by $S$. sclarea and S. chloroleuca showing $1.65 \pm 0.08$ and $1.65 \pm$ $0.21 \mathrm{mg} / \mathrm{g}$, while $S$. ceratophylla with $0.10 \pm 0.01 \mathrm{mg} / \mathrm{g}$ of RA in dried plant powder was the poorest.

In this regard, Wang et al developed an HPLC method for the determination of rosmarinic in rosemary, sage, thyme, spearmint, balm, and lavender. They injected directly crude methanol extract as sample using a gradient elution consisted of methanol: water: phosphoric acid. It was a simple and suitable method but with a long Run time of 25 minutes and a crowded chromatogram (15). In another study Bandoniene et al (16) developed LCMass chromatographic method for detection of RA in the leaves of Salvia species including S. officinalis, S. glutinosa,
S. aethiopis, S. sclarea, and Borago officinalis. They used an RP-18 column $(250 \times 3 \mathrm{~mm}, 5 \mu \mathrm{m})$ with a gradient system of water: acetic acid (98:2) and acetonitrile at a flow of $0.3 \mathrm{~mL} / \mathrm{min}$ at $280 \mathrm{~nm}$. It was a fast and simple LC-PDA-Mas tandem method but with long run time of 30 minutes. Calibration curve was calculated over a wide working range of $25-500 \mu \mathrm{g} / \mathrm{mL}$ and higher LOQ of 6 $\mu \mathrm{g} / \mathrm{mL}$. Unfortunately, this method was not validated in that paper. In another study by Lopez-Arnaldos et al in 1995, they used a spectrophotometric method to directly determine RA in unpurified methanol extracts by a complexation reaction with $\mathrm{Fe}^{2+}(17)$. It was a simple and fast chemical method but could not differentiate between RA and other caffeic acid derivatives closely related to RA and a more specific chromatographic method was preferred. Bonoli et al also reported a suitable fast method for determination of both carnosic and RAs in rosemary species by capillary zone electrophoresis with acceptable run time of 10 minutes and good selectivity (18).

The main problem in HPLC quantification of RA is complexity of the total extract of Salvia species which contains a variety of different phytochemicals that might interact with chromatogram peak of RA. On the other hand, RA in neutral $\mathrm{pH}$ solvent is ionized and attached to column silanol groups which lead to widening and tailing. RA has an ionizable structure which causes particular 

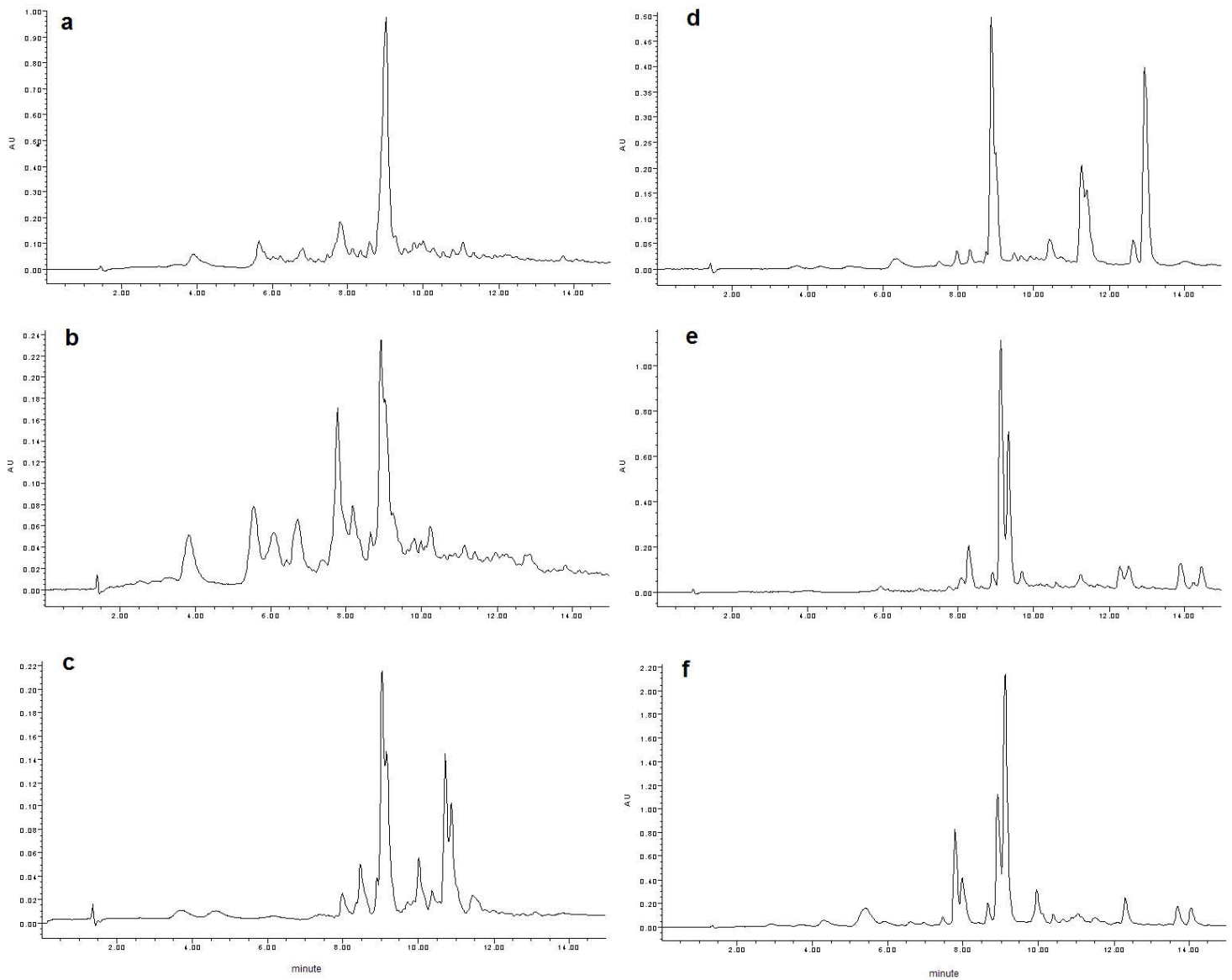

Figure 3. High performance liquid chromatography chromatograms of (a) Salvia virgata, (b) S. nemorosa, (c) S. ceratophylla, (d) S. macrosiphon, (e) S. sclarea, (f) S. chloroleuca.

Table 3. Rosmarinic acid assay $(\mathrm{mg} / \mathrm{g})$ in dried aerial parts of 6 sage species grows wild in North East of Iran

\begin{tabular}{lcc}
\hline Salvia species & Voucher No. & Rosmarinic acid (mg/g) \\
\hline S. ceratophylla & 36207 & $0.10 \pm 0.01$ \\
S. chloroleuca & 36528 & $1.65 \pm 0.21$ \\
S. macrosiphon & 43000 & $0.58 \pm 0.04$ \\
S. nemorosa & 40912 & $0.17 \pm 0.01$ \\
S. sclarea & 32961 & $1.65 \pm 0.08$ \\
S. virgata & 43965 & $3.50 \pm 0.12$ \\
\hline
\end{tabular}

separation challenges. The $\mathrm{pH}$ of mobile phase could be changed to influence the charge state of its ionized form in solution.

When the $\mathrm{pH}$ is equal to the $\mathrm{pKa}$ the $\mathrm{RA}$ rapidly converts between the ionized and non-ionized form and leads to a wide and asymmetric peak shape in HPLC. In fact, two forms of ionized and unionized species have different retention times. The ionized form with more polarity has smaller retention time in reversed phase HPLC. Therefore, in this study the effects of $\mathrm{pH}$ on mobile phase, flow, column temperature, and mobile phase composition on the column resolution, tailing factor, and retention time were optimized and a fast, easy and suitable validated HPLC method for RA assay in Salvia extracts or their pharmaceutical dosage forms were designed.

In sum, this validated HPLC method allows determination of amounts as low as $2.5 \mu \mathrm{g} / \mathrm{mL}$ of RA and linearity in the ranges of $2.5-25 \mu \mathrm{g} / \mathrm{mL}$ and $100-600 \mu \mathrm{g} / \mathrm{mL}$, which is suitable for standardization of Salvia species in traditional and pharmaceutical formulations.

\section{Acknowledgements}

The authors are grateful to MR. Jouharchi for collection and authentication of plants and also from Isfahan Pharmaceutical Science Research Centre in Isfahan University of Medical Science where the study was done.

\section{Authors' contributions}

MG coordinated the study and participated in most of the experiments. PM contributed to data analysis and writing and finalizing the manuscript. NS participated in most of the experiments. MM contributed to finalizing the manuscript. All authors read and confirmed final version and publication of the manuscript.

\section{Conflict of interests}

The authors have no conflicts of interest. 


\section{Ethical considerations}

Ethical consideration has been completely observed by the authors.

\section{Funding/Support}

It has been supported by Isfahan Pharmaceutical Sciences Research Center, Isfahan University of Medical Sciences (Grant No. 191034).

\section{References}

1. Hamidpour M, Hamidpour R, Hamidpour S, Shahlari M. Chemistry, pharmacology, and medicinal property of sage (Salvia) to Prevent and cure illnesses such as obesity, diabetes, depression, dementia, lupus, autism, heart disease, and cancer. J Tradit Complement Med. 2014;4(2):82-8. doi: 10.4103/2225-4110.130373.

2. Lu Y, Foo LY. Polyphenolics of Salvia--a review. Phytochemistry. 2002;59(2):117-40.

3. Perry NS, Bollen C, Perry EK, Ballard C. Salvia for dementia therapy: review of pharmacological activity and pilot tolerability clinical trial. Pharmacol Biochem Behav. 2003;75(3):651-9.

4. Iuvone T, De Filippis D, Esposito G, D’Amico A, Izzo AA. The spice sage and its active ingredient rosmarinic acid protect PC12 cells from amyloid-beta peptide-induced neurotoxicity. J Pharmacol Exp Ther. 2006;317(3):1143-9. doi: $10.1124 /$ jpet.105.099317.

5. Christensen KB, Jorgensen M, Kotowska D, Petersen RK, Kristiansen K, Christensen LP. Activation of the nuclear receptor PPARgamma by metabolites isolated from sage (Salvia officinalis L.). J Ethnopharmacol. 2010;132(1):12733. doi: 10.1016/j.jep.2010.07.054.

6. Shahtalebi MA, Ghanadian M, Farzan A, Shiri N, Shokri D, Fatemi SA. Deodorant effects of a sage extract stick: Antibacterial activity and sensory evaluation of axillary deodorancy. J Res Med Sci. 2013;18(10):833-9.

7. Bommer S, Klein P, Suter A. First time proof of sage's tolerability and efficacy in menopausal women with hot flushes. Adv Ther. 2011;28(6):490-500. doi: 10.1007/ s12325-011-0027-z.

8. Tepe B. Antioxidant potentials and rosmarinic acid levels of the methanolic extracts of Salvia virgata (Jacq),
Salvia staminea (Montbret \& Aucher ex Bentham) and Salvia verbenaca (L.) from Turkey. Bioresour Technol. 2008;99(6):1584-8. doi: 10.1016/j.biortech.2007.04.008.

9. Ghassemi N, Ghanadian M, Ghaemmaghami L, Kiani H. Development of a validated HPLC/photodiode array method for the determination of isomenthone in the aerial parts of Ziziphora tenuior L. Jundishapur J Nat Pharm Prod. 2013;8(4):180-6.

10. Snyder LR, Kirkland JJ, Glajch JL. Practical HPLC Method Development. John Wiley \& Sons; 2012.

11. United States Pharmacopeia and National Formulary (USP 35-NF 30), Vol 1. Rockville, MD: United States Pharmacopeia Convention; 2012.

12. Ermer J, Miller JH. Method validation in pharmaceutical analysis. A guide to best practice. Weinheim: Willey VCH Verlag GmbH \& Co. KGaA; 2005.

13. Shekarchi M, Hajimehdipoor H, Saeidnia S, Gohari AR, Hamedani MP. Comparative study of rosmarinic acid content in some plants of Labiatae family. Pharmacogn Mag. 2012;8(29):37-41. doi: 10.4103/0973-1296.93316.

14. Petersen M, Abdullah Y, Benner J, Eberle D, Gehlen K, Hucherig S, et al. Evolution of rosmarinic acid biosynthesis. Phytochemistry. 2009;70(15-16):1663-79. doi: 10.1016/j. phytochem.2009.05.010.

15. Wang H, Provan GJ, Helliwell K. Determination of rosmarinic acid and caffeic acid in aromatic herbs by HPLC. Food Chem. 2004;87(2):307-11. doi: 10.1016/j. foodchem.2003.12.029.

16. Bandoniene D, Murkovic M, Venskutonis PR. Determination of rosmarinic acid in sage and borage leaves by high-performance liquid chromatography with different detection methods. J Chromatogr Sci. 2005;43(7):372-6.

17. Lopez-Arnaldos T, Lopez-Serrano M, Barcelo AR, Calderon AA, Zapata JM. Spectrophotometric determination of rosmarinic acid in plant cell cultures by complexation with $\mathrm{Fe} 2+$ ions. Fresenius' Journal of Analytical Chemistry. 1995;351(2):311-4. doi: 10.1007/bf00321655.

18. Bonoli M, Pelillo M, Lercker G. Fast separation and determination of carnosic acid and rosmarinic acid in different rosemary (Rosmarinus officinalis) extracts by capillary zone electrophoresis with ultra violet-diode array detection. Chromatographia. 2003;57(7):505-12. doi: 10.1007/bf02492549. 